\title{
HYDROGEN ION TITRATION STUDY OF THE HISTIDINE RESIDUES OF HORSE MYOGLOBIN
}

\author{
L.H. M. JANSSEN, S.H. DE BRUIN and G. A.J. van Os \\ Department of Biophysical Chemistry, University of Nijmegen,Toernooiveld, \\ Nijmegen, The Netherlands
}

Received 4 May 1972

\begin{abstract}
The hydrogen ion titration curves of horse cyanometmyoglobin and metmyoglobin have been measured between pH 5.5 and 9.5. The most likely explanation of the titration results of cyanometmyoglobin is that 6 histidines are titratable with an intrinsic $p K$ of 6.8 and an electrostatic interaction factor $w$ of 0.150 ; in addition the results indicate that the total number of titratable carboxyl groups is 25 , two more than calculated from the covalent structure of horse myoglobin. The titration behavior of metmyoglobin is explicable assuming the presence of one extra group as compared to cyanometmyoglobin with a $p K$ near 9 , which contributes to the maximum positive charge.
\end{abstract}

One of the promising features of proton magnetic resonance in the study of proteins is the possibility to follow the titration of individual histidines. Recently such a study has been published concerning the titration behavior of histidines in horse myoglobin (1). The results show that at least 6 histidines have pK values between 6.7 and 7.2.

Because the normal acid-base titration curve of horse myoglobin has not yet been reported, we have undertaken this study in order to compare the results obtained with the two methods.

\section{MATERIALS AND METHODS}

Myoglobin from horse skeletal muscle (Baker, Holland, 1 x crystalline, lyophilised) was used in this study. MetMbCN (MetMb, metmyoglobin MetMbCN, cyanometmyoglobin) was prepared by addition of solid KCN to a MetMb solution. The protein solutions were prepared and titrated as described earlier (2). Three $\mathrm{ml}$ of the protein solutions, concentration about $1.5 \%$ (determined by drying to constant weight at $105^{\circ}$ ) were titrated at $25^{\circ}$ with approximately $0.08 \mathrm{M} \mathrm{NaOH}$ or $\mathrm{HCl}$, starting from the isoionic point. The change in protein charge after each addition of $0.01 \mathrm{ml}$ of titrant was about 0.3 , based on a molecular weight of 17,400 as calculated from the amino acid composition (3). Forward and back titration curves were reversible in the $\mathrm{pH}$ region studied.

The results are presented as normal titration curves ( $\mathrm{pH}$ versus $\overline{\mathbf{Z}}_{\mathrm{H}}$, where $\overline{\mathbf{Z}}_{\mathbf{H}}$ is the mean proton charge of the protein) and differential titration curves $\left(-\mathrm{dpH} / \mathrm{d} \overline{\mathbf{Z}}_{\mathbf{H}}\right.$ versus $\left.\overline{\mathbf{Z}}_{\mathrm{H}}\right)$ which represent the slope of a normal titration curve or which can be viewed as the reciprocal of the buffer capacity of the protein. The analysis of the latter kind of curves has been reported earlier (2). In this communication we will use the following equations:

$$
\mathrm{pH}=\mathrm{pK}_{\mathrm{i}}+\log \left(a_{\mathrm{i}} / 1-a_{\mathrm{i}}\right)-0.868 \mathrm{w} \overline{\mathbf{Z}}_{\mathrm{H}}
$$

where the symbols have their usual meaning, viz. $K_{i}$ the intrinsic dissociation constant of the $n_{i}$ groups of class $i, \alpha_{1}$ their degree of dissociation, $w$ the electrostatic interaction factor. For $\overline{\mathbf{Z}}_{\text {H }}$ we have

$$
\overline{\mathrm{Z}}_{\mathrm{H}}=\mathbf{Z}_{\max }-\Sigma \mathrm{n}_{\mathrm{i}} \boldsymbol{a}_{\mathrm{i}}
$$




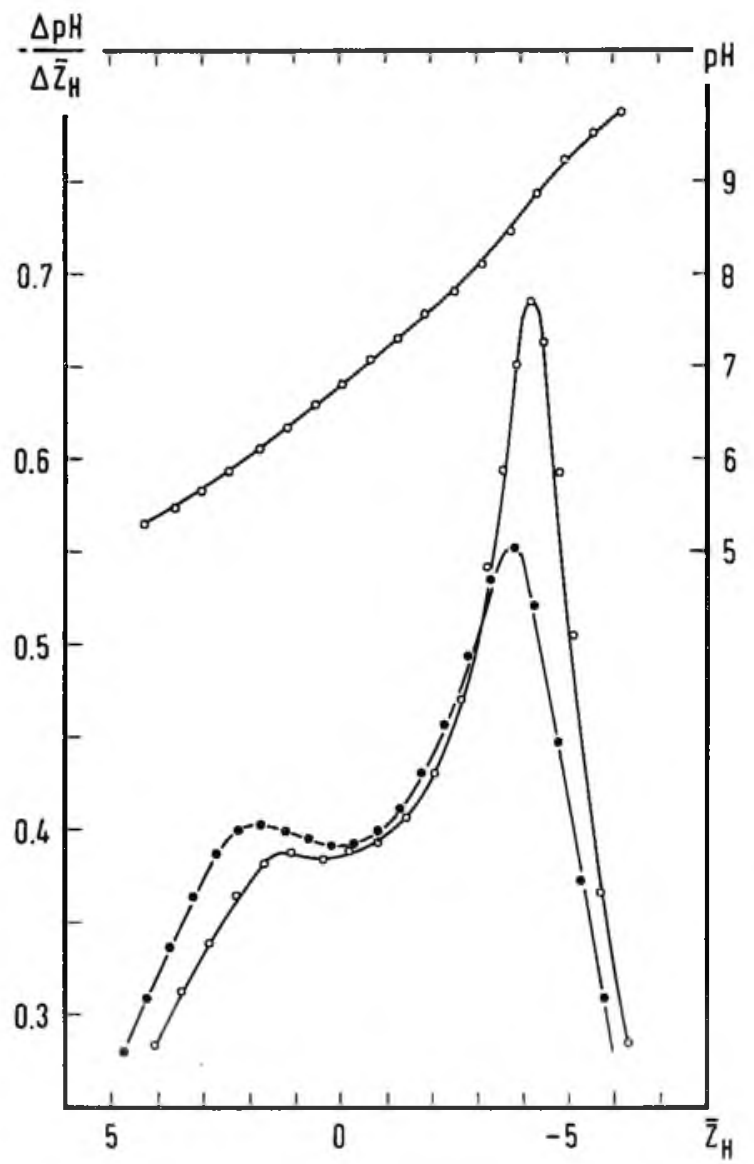

Figure 1

Differential titration curves of horse MetMb ( $\bullet$ ) and normal and differential titration curves of MetMbCN (o).

$Z_{\text {max }}$ represents the maximum positive charge of the protein being equal to the sum of the number of titratable histidines, lysines, arginines and the terminal amino group. Equation (2) can also be written as $(4,5)$

$$
\mathrm{n}_{\mathrm{His}} \alpha_{\mathrm{His}}=\mathrm{Z}_{\max }-\overline{\mathbf{Z}}_{\mathrm{H}}-\Sigma^{\prime} \mathrm{n}_{\mathrm{i}} \alpha_{\mathrm{i}}
$$

\section{RESULTS AND DISCUSSION}

Fig. 1 shows the normal and differential titration curve of horse MetMbCN and the differential titration curve of MetMb. We will discuss the results of MetMbCN first. Normally a differential titration curve shows two peaks which in good approximation can be considered as the titration end points of the carboxyl region and neutral region, respectively. In case of MetMbCN, however, only a shoulder is seen near $\overline{\mathrm{Z}}_{\mathrm{H}}=1.5 \mathrm{pH}$ 6.2). The second peak is fairly sharp and is found at $\bar{Z}_{\mathrm{H}}=-4.2$ (pH 8.9). As discussed earlier (2) this second peak will be found in a differential titration curve at a $\bar{Z}_{H}$ value given by $n_{L y s}+n_{A r g}$ $-\mathrm{n}_{\text {coor. }}$. The validity of this relation has been checked for the $\alpha$ and $\beta$ chains of human hemoglobin and several other hemoglobins $(2,5)$. There are 19 lysines and 2 arginines in horse myoglobin, so we expect 25 titratable carboxyl groups. The amino acid composition, however, shows 13 glutamic acids and 7 aspartic acids; adding to this the terminal carboxyl group and the two carboxyl groups from the heme group, we arrive at 23 carboxyl groups, two less than predicted by the differential titration curve. Our conclusion from this observation is that the amide content is two less than given by the amino acid analysis. It should be recognized that horse myoglobin is heterogeneous, containing three main fractions (6-8). The relative abundance of these fractions and their isoionic $\mathrm{pH}$ have been reported to be roughly $85 \%$ pH 7.2 (first fraction), $10 \%$ pH 6.8 (second fraction) and $5 \% \mathrm{pH} 6.5$ (third fraction) (8). From Fig. 1 one can see that $-\Delta \mathrm{pH} / \Delta \overline{\mathrm{Z}}_{\mathrm{H}}$ is near 0.4 in the $\mathrm{pH}$ region covering the isoionic $\mathrm{pH}$ of the three fractions. This means that two similar myoglobins differing by one charge unit should show a difference in isoionic pH of about 0.4. Therefore, the second and third fraction might possess, respectively, one and two carboxyl groups more than the main fraction. In view of the relative concentrations of the three fractions, this means that the difference between the number of carboxyl groups in the main fraction and the mean number of carboxyl groups in the mixture is not larger than 0.2 .

Usually the total number of titratable histidines and $\alpha$-amino groups can be taken as equal to the peak-to-peak distance in a differential titration curve. However, in the curve for MetMbCN the shoulder at $\overline{\mathrm{Z}}_{\mathrm{H}}=1.5$ (pH 6.2) is not sharp enough to be considered as a real equivalence point. This means that the distance of 5.7 charge units between the position of the shoulder and the right peak is to be considered as a very minimum for the total number of groups titratable in the neutral region. This is also reflected by the relatively high $\mathrm{pH}$ of 6.2 at $\overline{\mathbf{Z}}_{\mathbf{H}}=1.5$. Normally, when the first peak is well resolved this $\mathrm{pH}$ is about 5.5 (2). As for MetMbCN $\bar{Z}_{\mathrm{H}}$ being about 3 at this pH, we think that a number of about 7.5 


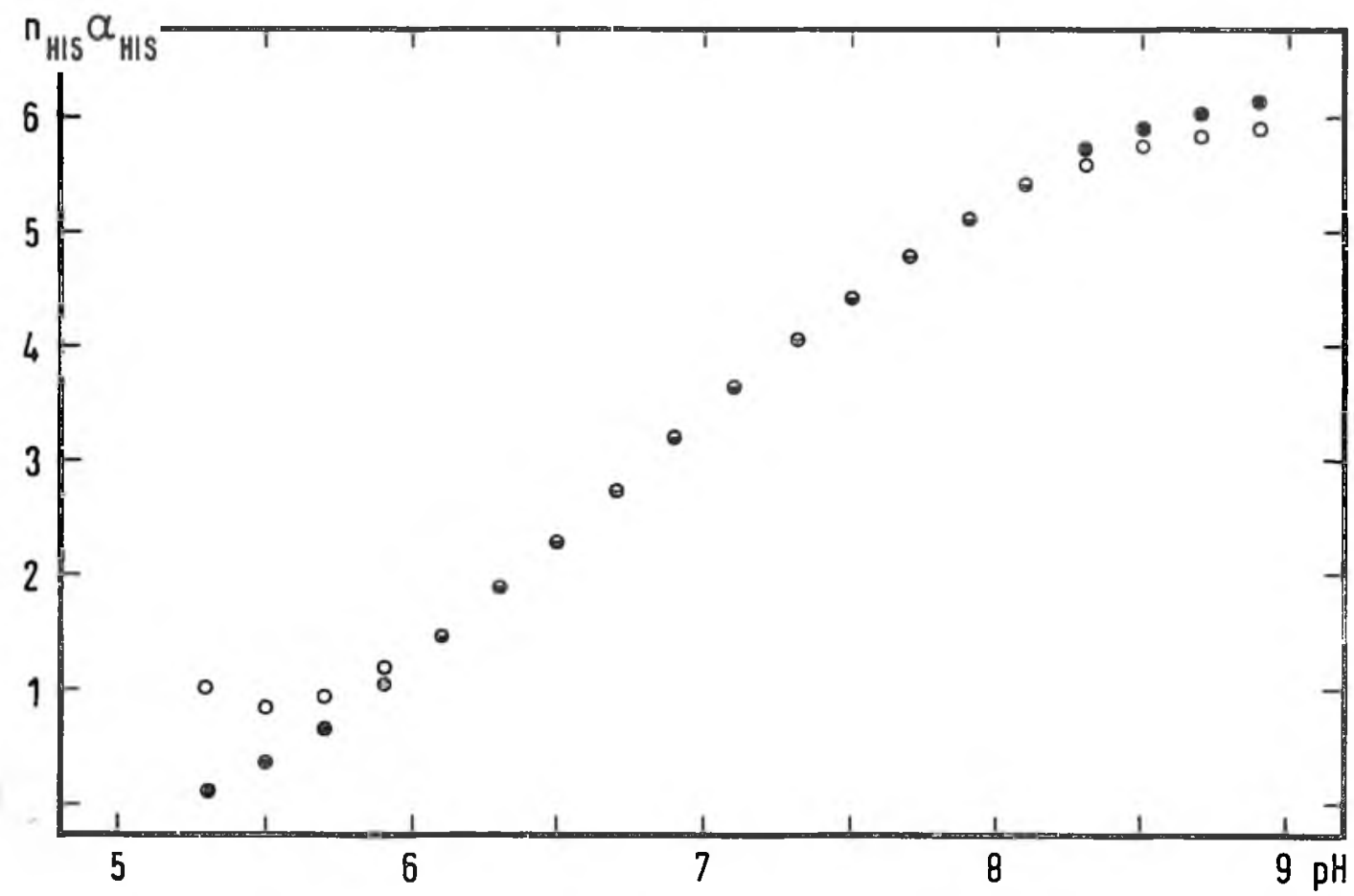

FIGURE 2

Titration of histidines in horse MetMbCN. The calculation procedure has been described in detail in the text; $(0) \mathrm{w}=0$ and $(\bullet) \mathrm{w}=0.058$.

groups titratable in the neutral region is more likely; so in the first approximation we arrive at 6 to 7 titratable histidines.

In order to obtain more information about the number and $\mathrm{pK}$ of the titratable histidines we applied Equation 2. $\mathbf{Z}_{\max }$ was calculated from the amino acid composition, assuming 6 titratable histidines. The exact value of $\mathrm{Z}_{\max }$ is of minor importance because any other value for $\mathbf{Z}_{\max }$ causes only a vertical shift in a plot of $\mathrm{n}_{\text {His }} \alpha_{\text {His }}$ versus $\mathrm{pH}$. The term $\Sigma^{\prime} \mathrm{n}_{1} \alpha_{1}$ comprises the carboxyl, $a$-amino, lysyl and tyrosyl residues. As discussed above, we considered the presence of 5 carboxyl groups; the lysines and tyrosines were taken as one class with an intrinsic pK of 10.3 as found for the $\beta$ chains (2) and a pK of 8.0 was assigned to the terminal group. As regards the $\mathrm{pK}$ of the carboxyl groups, we assumed a pK of 4.3 in analogy with the $\beta$-chains. There a pK of 4.1 for the aspartyl and 4.5 for the glutamyl residues was assumed, but a mean pK of 4.3 displayed equally good results. $\overline{\mathbf{Z}}_{\mathrm{H}}$ is determined experimentally. Fig. 2 shows two plots of $n_{\text {His }} \alpha_{\text {His }}$ versus
$\mathrm{pH}$ calculated with $\mathrm{w}=0$ and $\mathrm{w}=0.058$ (this latter value again as for the $\alpha$ and $\beta$ chains). The choice of $\mathrm{pK}$ and $w$ is important because of their influence on the limiting values of $\mathrm{n}_{\mathrm{His}} \alpha_{\mathrm{His}}$, especially on the acid side. It will be clear that increasing $\mathrm{w}$ and decreasing the $\mathrm{pK}$ of the carboxyl groups have similar influence on the acid side of the plots in Fig. 2 (see Equation 1). From this figure one may conclude that a number of 5 titratable histidines is somewhat too small and that more likely 6 or 7 histidines are titratable. The uncertainty is mainly caused by the impossibility of extending the titration to $\mathrm{pH}$ values low enough to determine the $\mathrm{pK}$ and $\mathrm{w}$ of the carboxyl groups unambiguously, because of the fact that myoglobin denatures at low $\mathrm{pH}$. On the other hand, as can be seen in Fig. 2, the influence of the choice of $\mathrm{w}$ and $\mathrm{pK}$ on $\mathrm{n}_{\text {His }} \alpha_{\text {His }}$ becomes small in the $\mathrm{pH}$ region 6 to 8 . Thus, if the titration of the histidines obeys Equation 1, then a plot of $\mathrm{pH}-\mathrm{log}$ $(\alpha / 1-\alpha)$ versus $\bar{Z}_{\mathrm{H}}(\alpha$ representing the degree of dissociation of the histidines) should be straight and may be used for the determination of $\mathrm{pK}$ and 


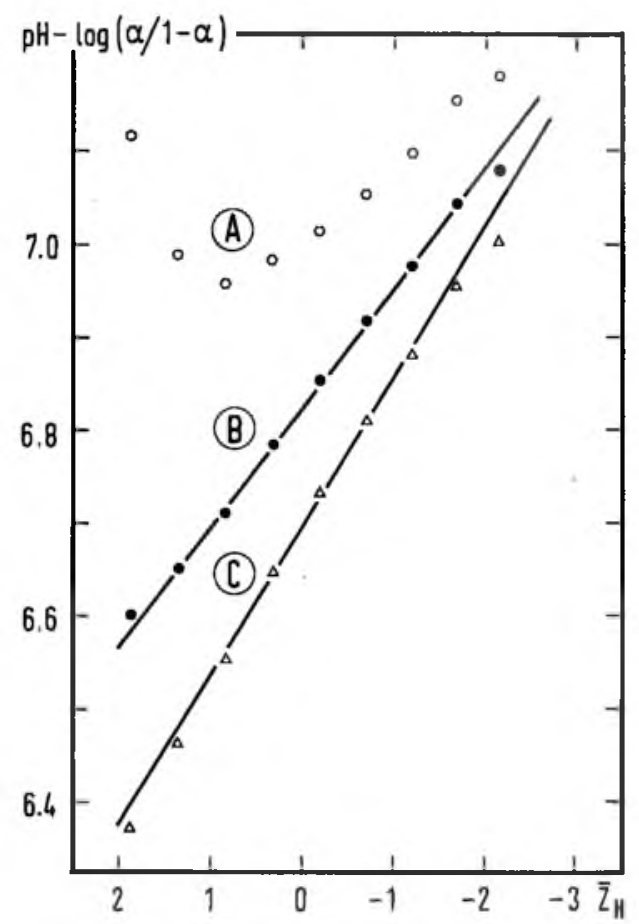

FIGURE 3

Determination of $\mathrm{pK}_{\mathbf{i}}$ and $\mathrm{w}$ for the histidines in horse MetMbCN, assuming 5 (curve A), 6 (curve B) and 7 (curve C) titratable histidines.

$\mathrm{w}$ for the histidines. This has been done for $\mathrm{n}_{\mathrm{His}}$ equal to 5, 6 and 7 (Fig. 3). Only with $\mathrm{n}_{\mathrm{His}} 6$ or 7 is a straight line obtained, which makes a number of 5 titratable histidines less likely. Assuming 6 groups we find $\mathrm{w}=0.150$ and $\mathrm{pK}$ near 6.8 and using 7 groups w becomes 0.185 and pK 6.7. Both pK's are very reasonable, but the electrostatic interaction factor obtained in both cases is somewhat high; the theoretical $\mathrm{w}$, based on the radius of the molecule (9) is 0.096 . Taking the magnitude of $w$ as a criterion, we would say that most likely the number of titratable histidines in horse myoglobin is 6. The corresponding intrinsic $\mathrm{pK}$ of 6.8 represents a mean $\mathrm{pK}$. Differences in $\mathrm{pK}$ between groups in one class amounting to several tenths have been found to have little influence on the linearity of a plot as shown in Fig. 3. Theoretical calculations based on Equation 1 have also shown that such heterogeneity in pK may be (at least partially) the cause of the higher electrostatic interaction factor.
It should be noted that Thomson et al. (1), in their NMR study have used carboxymyoglobin, whereas we used MetMbCN. It is, however, not very likely that the spin or oxidation state of the iron will influence the number of titratable histidines. Therefore, in Fig. 1, the differential titration curve of MetMb is also shown. The acid part of this curve is shifted about one charge unit as compared with MetMbCN. This means that $\mathbf{Z}_{\max }$ in MetMb is one unit higher than in MetMbCN. In both components the oxidation state of the heme iron is +3 , but in MetMbCN the $\mathrm{Fe}^{3+}$ is coordinated with $\mathrm{CN}^{-}$, so in $\mathrm{MetMb}$ a neutral ligand must be present in the acid region. It is commonly assumed that the sixth coordination place is occupied in this compound by a water molecule, which at higher $\mathrm{pH}$ becomes replaced by an $\mathrm{OH}^{-}$ ion, so that in Metb an extra titratable group is present. The $\mathrm{pK}$ of this group is near 9 (10). This explains the lower height of the second peak and its shift to higher $\overline{\mathbf{Z}}_{\mathrm{H}}$ value because the degree of dissociation of this extra groun is near 0.5 at the $\mathrm{pH}$ of the second peak. The di ference between MetMb and MetMbCN is therefore fully explicable, assuming the presence of an extra group which contributes to $Z_{\max }$, having a pK near 9. The number of titratable histidines should be the same in both components. Unexplained remains the fact that the shoulder is somewhat higher in MetMb than in MetMbCN.

\section{REFERENCES}

1. Thompson, J. C., HaAr, W., MAURER, W., RuterJANS, H., Gersonde, K., and Sick, H., FEBS Letters, 16, 262-266 (1971).

2. JANSSEN, L.H.M., DE BruIN, S. H., and vaN Os, G.A.J., Biochem. Biophys. Acta, 221, 214-227 (1970).

3. Dautrevaux, M., Boulanger, Y., Han, K., and Biserte, G., European J. Biochem., 11, 267-277 (1969).

4. TANFord, C., and Nozaki, Y., J. Biol. Chem., 241, 2832-2839 (1966).

5. JANSSEN, L.H.M., De Bruin, S. H., and vaN OF G. A. J., J. Biol. Chem., 247, 1743-1749 (1972).

6. Åkeson, A., and Theorell, H., Arch. Biochem. Biophys., 91, 319-325 (1960).

7. Vesterberg, O., Acta Chem. Scand., 21, 206-216 (1967).

8. VAN DEN OORD, A.H.A., WeSDORP, J.J., VAN DAM, A. F., and VerHEY, J. A., European J. Biochem., 10, 140-145 (1969).

9. TANFORD, C., Physical chemistry of macromolecules, Wiley, New York, 1961.

10. George, P., and Hanania, G., Biochem. $J ., 52$, 517-523 (1952). 


\title{
HYDROGEN ION TITRATION CURVES OF PROTEINS AS A SOURCE OF STRUCTURAL AND FUNCTIONAL INFORMATION *
}

\author{
G. A. J. VAN OS, S. H. DE BRUIN and L. H. M. JANSSEN \\ Department of Biophysical Chemistry, University of Nijmegen, Nijmegen (The Netherlands) \\ (Received 2nd October 1971)
}

\section{INTRODUCTION}

Protein molecules generally consist of one or more polypeptide chains. These chains are built up from about twenty different amino acids, coupled by peptide bonds. The side chains of these amino acids can be uncharged, positively charged, as those of the lysine and histidine residues, or negatively charged, such as the carboxyl groups. By titrating a solution of a protein with a strong acid or base, data can be obtained about the number of the various proton donor groups, their $\mathrm{p} K$, etc. The method became quite popular between 1950 and 1960, as a result of the important work of investigators such as Tanford, Steinhardt and others ${ }^{1,2}$, but interest in it declined somewhat when around 1960 the first X-ray analyses of protein molecules became available ${ }^{3,4}$. It soon became clear, however, that several functional properties of protein molecules could not be explained in terms of the X-ray model alone. Other methods were needed to complete the picture and among these the determination of hydrogen ion titration curves is still of value.

\section{BASIC PROPERTIES OF PROTEIN TITRATION CURVES}

The upper curve in Fig. 1 schematically shows a titration curve ${ }^{5}$. The $\mathrm{pH}$ of the protein solution is plotted $v$ s. the mean number of protons bound by the molecule $\left(\bar{Z}_{\mathrm{H}}\right)$, with the isoionic point as reference. An isoionic solution $\left(\bar{Z}_{\mathrm{H}}=0\right)$ can be obtained by deionizing the protein solution. The charge can then be made positive or negative by adding $\mathrm{HCl}$ or $\mathrm{NaOH}$, respectively. From the known amount of added acid or base and the known number of moles of the protein, the charge of the protein molecule can easily be calculated. Correction for free $\mathrm{H}^{+}$- or $\mathrm{OH}^{-}$-ions is only necessary at low and high $\mathrm{pH}$ values. Outside the $\mathrm{pH}$-region of 4-10 shown in Fig. 1 many proteins undergo conformational changes, usually irreversible but in the acid region sometimes reversible. As can be seen, the titration curve has some inflection points in the region shown. The positions of these points become much clearer in the differential titration curve (lower curve of Fig. 1), representing $-\mathrm{dpH} / \mathrm{d} \bar{Z}_{\mathrm{H}}$ as a function of $\bar{Z}_{\mathrm{H}}$, where these points appear as maxima and minima. The significance of the two peaks can be understood as follows. Suppose the $\mathrm{pH}$ is made so low that all proton donor groups have taken

\footnotetext{
* Dedicated to Professor J. Th. G. Overbeek on the occasion of the 25 th anniversary of his appointment as a Professor of Physical Chemistry.
} 


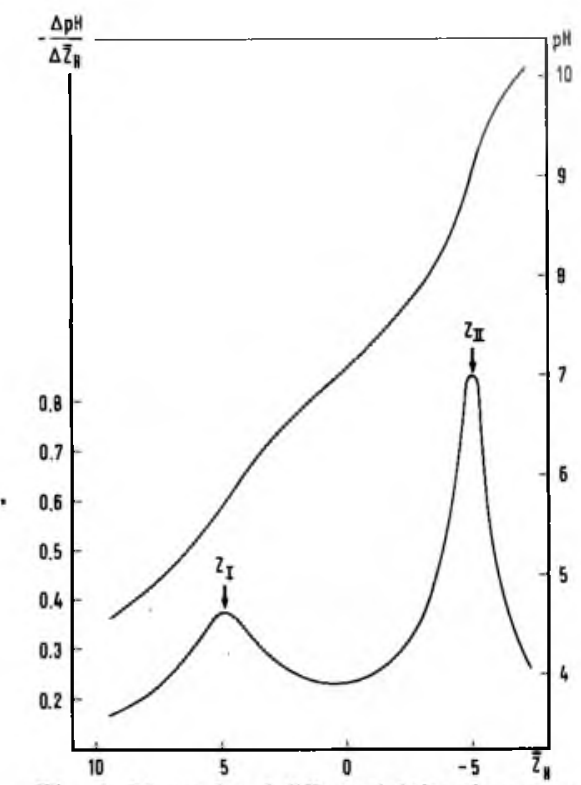

Fig. 1. Normal and differential titration curve of a protein molecule having : 20 titratable carboxyl groups, $\mathrm{p} K=4.5 ; 9$ titratable imidazole groups, $\mathrm{p} K=7 ; 1 \alpha$-amino group, $\mathrm{p} K=8 ; 15$-amino groups, $\mathrm{p} K=10.5$. Only the $\mathrm{pH}$-region from 4 to 10 is shown.

up a proton. The molecule then has its maximum positive charge $\left(Z_{\max }\right)$. Upon addition of a base, first the groups with the lowest $\mathrm{p} K$ (the $\alpha$ - and side-chain carboxyl groups, $\mathrm{p} K \approx 4$ ) begin to loose their protons. Then the groups with a $\mathrm{p} K$ in the neutral region (imidazole groups, $\alpha$-amino groups, $\mathrm{p} K$ 6-8) dissociate, followed by the groups with a high $\mathrm{pK}$ ( $\varepsilon$-amino groups, phenolic-OH groups, $-\mathrm{SH}$ groups, with a $\mathrm{p} K$ between 10 and 11 and the strong basic arginine residues with $\mathrm{p} K>12$ ). The peak at $Z_{\mathrm{I}}$ can as a first approximation be considered as the titration endpoint of the carboxyl groups and the second at $Z_{\mathrm{II}}$ as that of the neutral groups. Information can thus be obtained about the number of titratable groups in the neutral and acid region, and by comparison with the amino acid analysis, groups which are not titratable (for example imidazole groups buried in the interior of the molecule, carboxyl groups in the amide form) can be detected. The $\mathrm{p} K$ values of the various classes of groups can be roughly estimated, and by comparing the experimental curves with calculated ones (see next section) more accurate $\mathrm{p} K$ values can be obtained. Often difference titration curves, obtained by subtracting two normal titration curves are also valuable. These may be curves of a protein in two different forms such as deoxyhaemoglobin and oxyhaemoglobin, or two proteins which show minor differences such as bovine haemoglobin A and B (see below) or curves of a protein and a chemical modification of this protein. A number of examples will be given in the last section.

\section{THEORY OF TITRATION CURVES}

The analysis of a protein titration curve is usually based on the following equations $^{6}$ : 


$$
\begin{aligned}
& \mathrm{pH}=\mathrm{p} K_{\mathrm{i}}+\log \frac{\alpha_{\mathrm{i}}}{1-\alpha_{\mathrm{i}}}-0.868 w Z \\
& \bar{Z}_{\mathbf{H}}=Z_{\max }-\Sigma n_{\mathrm{i}} \alpha_{\mathrm{i}}
\end{aligned}
$$

where $\mathrm{p} K_{\mathrm{i}}$ is the intrinsic dissociation constant of the $n_{\mathrm{i}}$ groups of class $\mathrm{i}, \alpha_{\mathrm{i}}$ their degree of dissociation, $w$ the electrostatic interaction factor and $Z$ the protein charge. The latter is equal to $\bar{Z}_{\mathrm{H}}$ when only protons are bound. The apparent $\mathrm{p} K$ (sum of $\mathrm{p} K_{\mathrm{i}}$ and $-0.868 w Z$ ) is a function of $Z$ and is only equal to $\mathrm{p} K_{\mathrm{i}}$ at $Z=0$. For charges different from zero the difference between $\mathrm{p} K$ and $\mathrm{p} K_{\mathrm{i}}(-0.868 \mathrm{wZ})$ is the same for all groups and independent of the way in which the individual charges are distributed over the molecule. This is of course an approximation, but in practice it works quite satisfactorily. The electrostatic interaction factor $w$ depends on the shape and dimensions of the molecule and on temperature and ionic strength. For a spherical molecule, impenetrable to small ions and with a spherically symmetrical charge distribution, $w$ is given by:

$$
w=\frac{\varepsilon^{2}}{2 D R k T}\left(1-\frac{\kappa R}{1+\kappa a}\right)
$$

where $\varepsilon$ is the elementary charge, $D$ the dielectric constant of the solvent, $k$ Boltzmann's constant, $T$ the absolute temperature, $R$ the radius of the sphere, $\kappa$ the DebyeHuickel parameter and $a$ the distance of closest approach of a counterion and the protein molecule. Other expressions for $w$ are obtained when the spherical particle is completely or partially penetrable for solvent and small ions ${ }^{6-8}$, or when the positions of the individual charges are taken into account ${ }^{9}$.

All formulae for $w$ contain the parameter $\kappa$, so that $w$, and thus also the course of a titration curve, is ionic strength dependent. Otherwise it should be noted that $w$, apart from theoretical considerations, is an experimentally accessible quantity.

For differential titration curves the following expression has been derived from eqns. (1) and (2) ${ }^{10}$ :

$$
-\frac{\mathrm{dpH}}{\mathrm{d} \bar{Z}_{\mathrm{H}}}=\frac{1}{2.303 \Sigma n_{\mathrm{i}} \alpha_{\mathrm{i}}\left(1-\alpha_{\mathrm{i}}\right)}+0.868 w
$$

This assumes that only protons are bound and that the conformation of the protein molecule is $\mathrm{pH}$-independent, so that $w$ is constant. Under these circumstances a change in ionic strength, and thus of $w$, causes only a vertical shift of the differential titration curve, without affecting its shape. On the other hand, if the shape of the curve is seriously influenced by changes in ionic strength, this is a strong indication of conformational changes.

With the aid of eqns. (1), (2) and (4) the normal and differential curve can be calculated if suitable values are chosen for the various parameters. In fact, the curves of Fig. 1 are curves calculated in this way using the parameters mentioned in the legend. Although much information can be gathered from the experimental results alone, without extensive calculation, more detailed information can be obtained by such a calculation procedure. A computer programme is then used, based on eqns. (1), (2) and (4), by which the experimental titration curves are simulated. 
EXPERIMENTAL :

Equipment for the determination of titration curves with high accuracy, is shown in Fig. 2. The microburette (Metrohm, type E457) contains a precision machined tantalum rod, moving in a somewhat wider glass tube by means of a screw. The rod drives the titrant via a very fine capillary into the titration vessel, which is thermostatted at the desired temperature. One revolution of the screw corresponds to $0.01 \mathrm{ml} \pm 0.2 \%$. The accuracy of the burette is determined by the precision of the metal rod (and screw) and can therefore be much better than that of a burette with glass cylinder and piston. The titration vessel usually contains $3 \mathrm{ml}$ of the protein solution, in which a glass- and calomel electrode (Radiometer types G202B and K401, respectively) are placed. The ionic strength is usually adjusted with $\mathrm{KCl}$ which, if necessary, is also added to the titrant to maintain a constant ionic strength during titration.

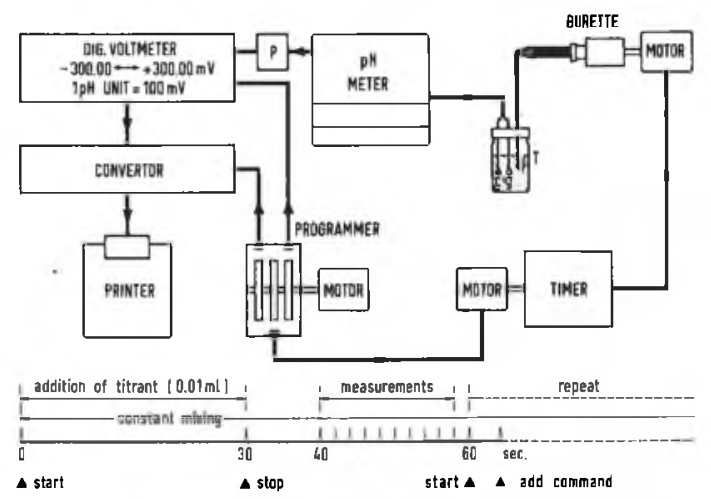

Fig. 2. Schematic diagram of automatic titration equipment. (T) Titration vessel, (g) glass electrode, (c) calomel electrode with very small $\mathrm{KCl}$ leak. The $\mathrm{pH}$-meter must have a very low drift; Radiometer chopper type PHM 26 was found to meet this requirement. The potentiometer $P$ is adjusted to give $100.00 \mathrm{mV}$ per $\mathrm{pH}$-unit. The digital voltmeter (Solartron type LM 1867) has a resolution of $10 \mu \mathrm{V}$ and also a low drift. The three synchronous motors with adjustable gear boxes (Halstrup type $M$ 64/10) allow speeds of 0.01-10 rev. $\min ^{-1}$.

Titrations are carried out under $\mathrm{N}_{2}, \mathrm{Ar}$ or $\mathrm{O}_{2}$ as desired. The $\mathrm{pH}$ is measured with a $\mathrm{pH}$-meter in combination with a high resolution digital voltmeter. Because the solution must reach equilibrium after each addition, the titrations are carried out discontinuously. A differential titration curve is obtained by plotting the $\mathrm{pH}$-difference after each two successive additions $v s . \bar{Z}_{\mathrm{H}}$. Both $\mathrm{pH}$-meter and digital voltmeter must therefore have a very low drift. To obtain the highest possible reproducibility the whole system is automated by means of a mechanical programmer consisting of three coaxial disks. Studs mounted on the disks operate micro switches which control the units. The titration cycle normally used, giving one point of the titration curve, is shown at the bottom of Fig. 1. After mixing, $10 \mathrm{pH}$-readings are taken and printed; these are then added, giving directly the mean value. The effect of fluctuations, which are always present, can thus be minimized.

In this way a very significant increase in accuracy for $\mathrm{pH}$-differences has been obtained. The accuracy of absolute pH-values is not so much increased, because it is limited by factors such as buffer precision, liquid junction phenomena, response of 

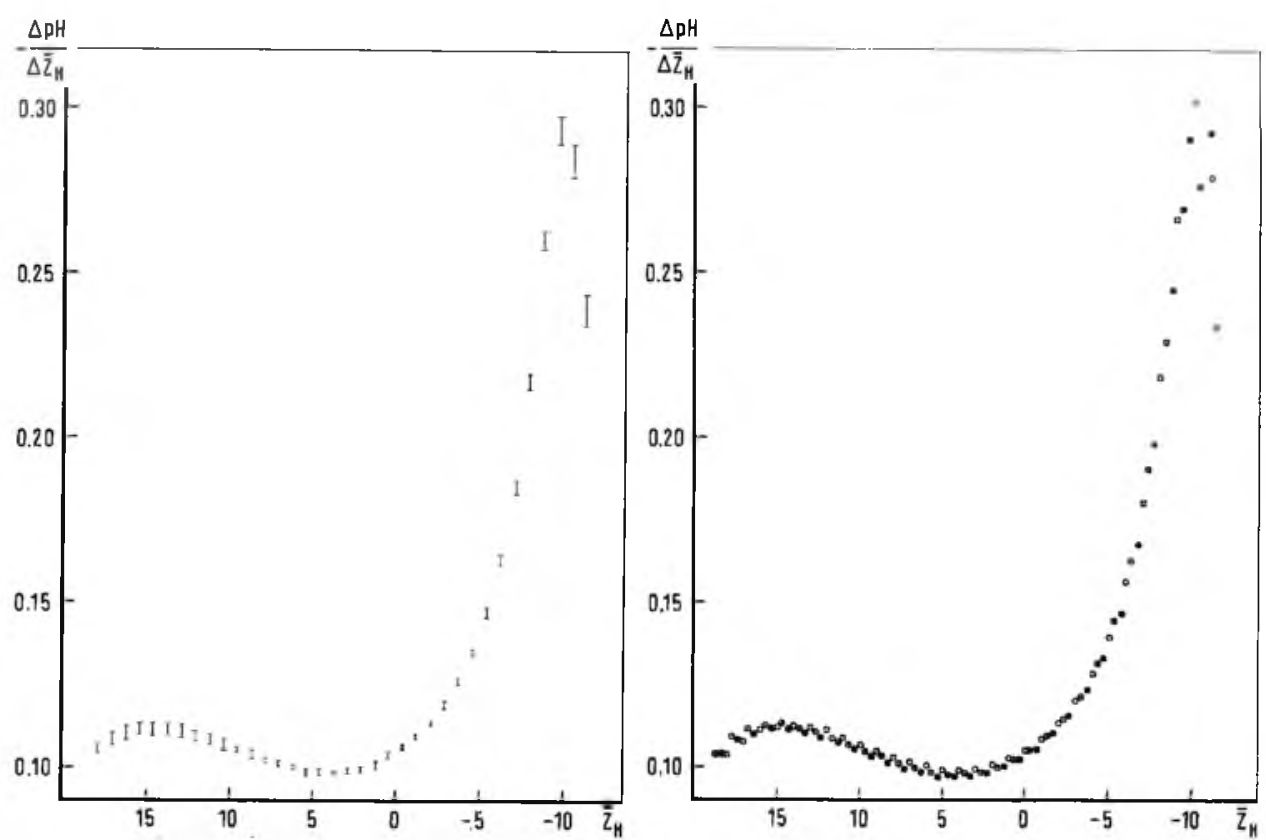

Fig. 3. Differential titration curve of human oxyhaemoglobin. $I$ (ionic strength) $=0.1 ; t=25^{\circ} \mathrm{C}$. Two complete forward as well as back titration curves were measured.

Fig. 4. Differential titration curve of human oxyhemoglobin. Three different samples, prepared at intervals of several months were titrated. For each sample the mean of one forward and one back titration is plotted. $I=0.1 ; t=25^{\circ} \mathrm{C}$.

the electrode, etc. Figure 3 gives the differential titration curve of human oxyhaemoglobin 5 . One sample was titrated twice forward and twice backward. Each bar contains four measurements, the endpoints representing the highest and lowest value. Figure 4 gives the titration curves of three different samples of oxyhaemoglobin, prepared at intervals of several months ${ }^{5}$. From Figs. 3 and 4 it can be seen that an overall accuracy in $\mathrm{dpH} / \mathrm{d} \bar{Z}_{\mathrm{H}}$ of about $\pm 2 \%$ has been reached.

\section{SOME EXAMPLES}

The first example of the use of titration curves concerns the study of a conformational change of a protein, in this case the serum albumin molecule. This molecule has a charge-independent conformation around its isoelectric point (5.2) in the $\mathrm{pH}$ region from about 4.5 to 6.5 . Outside this region conformational changes have been observed. Between approximately $\mathrm{pH} 6.0$ and 9.0 some rearrangement in the molecule takes place, called the neutral transition ${ }^{11,12}$. Figure 5 gives the differential titration curves of albumin at two ionic strengths ${ }^{13}$. Between $\bar{Z}_{\mathrm{H}}=0(\mathrm{pH}=5.2)$ and $\bar{Z}_{\mathrm{H}}=-12$ $(\mathrm{pH} \approx 7.2)$ the two curves are similar in shape and the vertical distance is approximately constant, which is consistent with a stable conformation. Between $\bar{Z}_{\mathbf{H}}=-12$ and $\bar{Z}_{\mathrm{H}}=-26(\mathrm{pH} \approx 9.5)$ however, there is no constant vertical distance between the curves, indicating a conformational change. The transition is influenced by the nature 

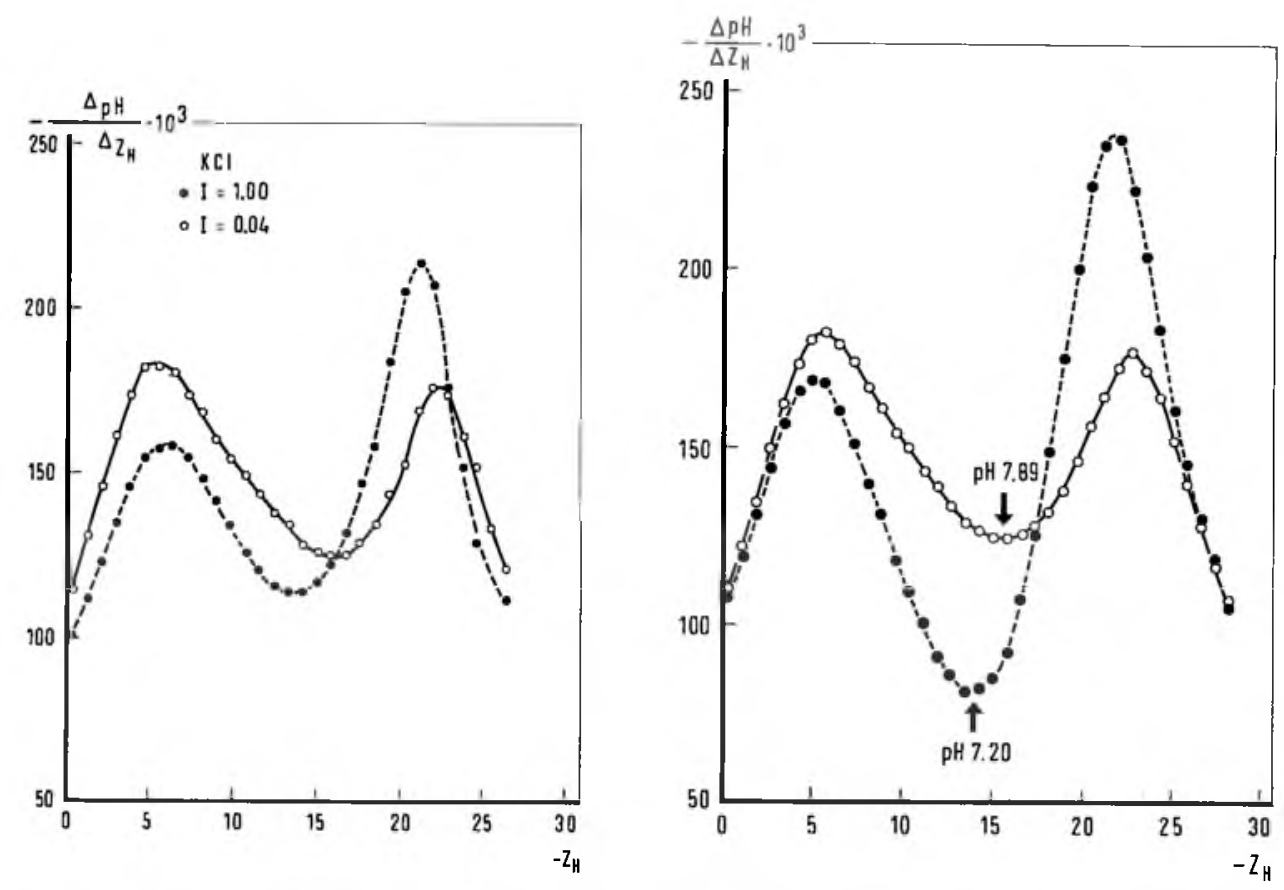

Fig. 5. Differential titration curves of bovine serum albumin at two ionic strengths, adjusted with $\mathrm{KCl}$. $I:(\mathrm{O})=1.00,(\mathrm{O}) 0.04 ; t=25^{\circ} \mathrm{C}$.

Fig. 6. Differential titration curves of bovine serum albumin, both at ionic strength 0.06 , adjusted with: (O) $\mathrm{KCl},(\mathrm{O}) \mathrm{CaCl}_{2} ; t=25^{\circ} \mathrm{C}$.

of the counterion ${ }^{14}$, as is demonstrated in Fig. 6, which presents the differential titration curves at the same ionic strength but with two different counterions viz. $\mathrm{K}^{+}$and $\mathrm{Ca}^{2+}$. The curve obtained in the presence of $\mathrm{CaCl}_{2}$, and especially its very deep minimum at $\mathrm{pH}=7.2$, has led us to the conclusion that during the neutral transition imidazole groups of histidine residues are set free, which below $\mathrm{pH} 6$ take part in salt bridges with $\mathrm{COO}^{-}$-groups. This influence of $\mathrm{Ca}^{2+}$-ions has been confirmed by ORD-measurements ${ }^{14}$.

Another example of the use of titration curves is given in Figs. 7 and 8 which present the normal and differential curves and the difference curve of horse deoxy- and oxyhaemoglobin ${ }^{5}$. The distance between the two peaks in the differential curve of deoxyhaemoglobin indicated that 26 groups are titrated between these peaks. Because the molecule contains four peptide chains (two $\alpha$-and two $\beta$-chains) there are four $\alpha$-amino groups in this region. Thus, out of a total number of 38 histidines (found from the amino acid analysis) only 22 are titratable and 16 of these residues must be masked. Upon oxygenation there is a rather drastic change in shape and position of the left-hand peak of the differential curve. This is due to a conformational change, resulting in a $\mathrm{pK}$ shift of four groups in the neutral region and four groups in the acid region $^{15}$. This effect, known as the Bohr effect, is physiologically important because it implies that a lowering of the $\mathrm{pH}$ (as occurring in the tissues, due to $\mathrm{CO}_{2}$ production) promotes liberation of oxygen from the haemoglobin. Using the data of the amino 

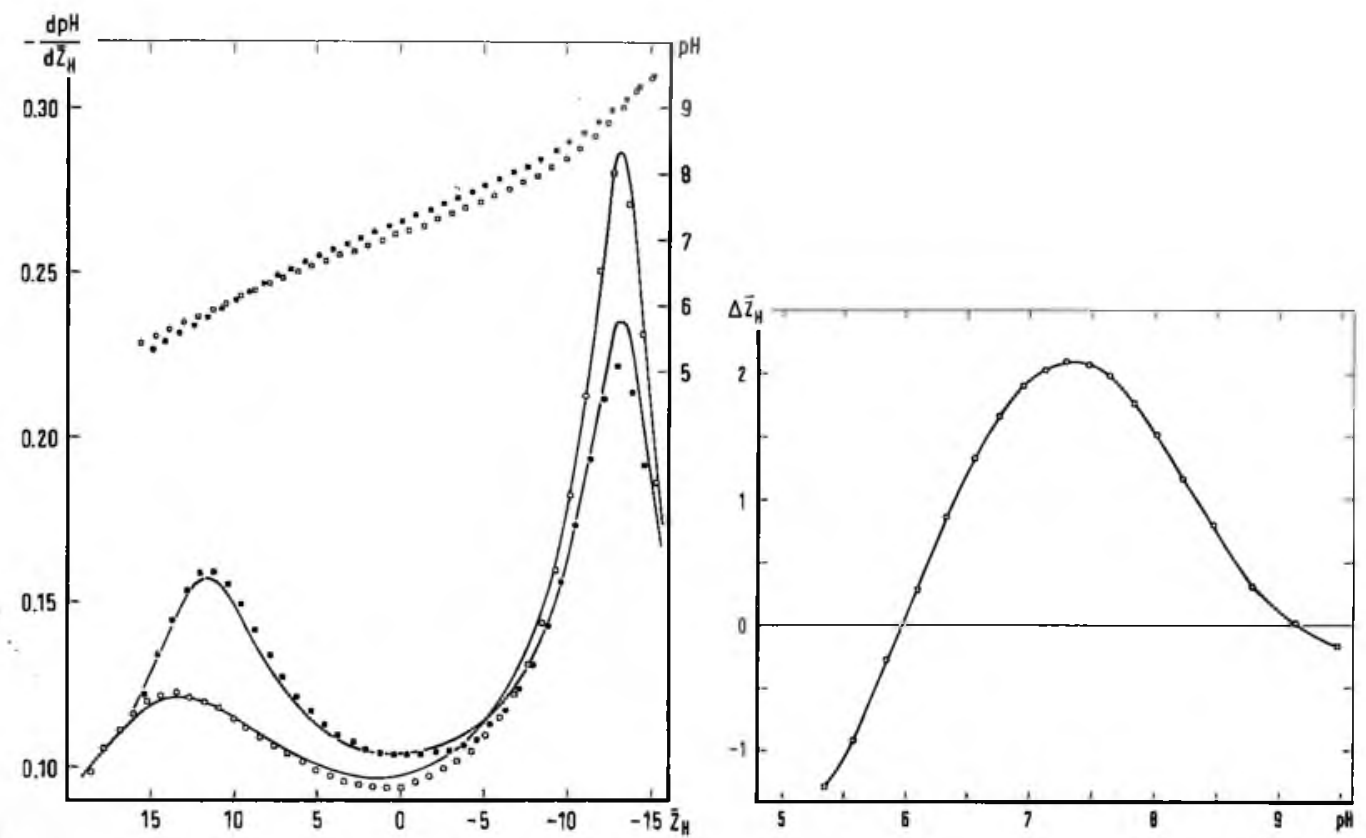

Fig. 7. Normal and differential titration curves of horse deoxy- (9) and oxyhaemoglobin (O). $I=0.1$ $(\mathrm{KCl}) ; t=25^{\circ} \mathrm{C}$. Drawn lines have been calculated.

Fig. 8. Difference titration curve of horse deoxy- and oxyhaemoglobin, derived from the normal titration curves of Fig. 7.

acid analysis, combined with those of the histidine residues, the curves were simulated by the calculation procedure mentioned above (drawn lines in Fig. 7). In this way we could confirm the finding of Antonini et al. ${ }^{16}$ that the $\mathrm{p} K$ of four groups shifts from 8 to 6.7 (normal or alkaline Bohr groups) and that of four other groups from 5.3 to 5.9 (acid Bohr groups) ${ }^{5}$. The effect of these $\mathrm{p} K$ shifts is very clearly seen in the difference curve of Fig. 8, which is directly related to the $\mathrm{pH}$-dependence of the oxygen affinity ${ }^{15}$.

The identity of the Bohr groups is still unresolved. It has been suggested that two of the alkaline Bohr groups are the $\alpha$-amino groups of the $\alpha$-chains ${ }^{17,18}$ with a $\mathrm{p} K$ of 6.7 in oxyhaemoglobin ${ }^{19}$ in which these groups show a high rotational freedom. In order to see if this low $\mathrm{p} K$ is due to an interaction between the chains in the tetramer, the $\mathrm{p} K$ of this group has been studied in the free $\alpha$-chains, in which the $\alpha$-amino group has at least as large a rotational freedom as in the tetramer. Figures 9 and 10 show the results of an attempt to determine the $\mathrm{p} K$ of this $\mathrm{N}$ terminus in the free $\alpha$-chains by blocking this group by reaction with fluorodinitrobenzene ${ }^{20}$. Figure 9 gives the differential titration curve of the blocked and unblocked chains, showing that in the blocked chain one group less is titrated between the two peaks. This is also seen in the difference titration curve of Fig. 10, from which, moreover, an apparent $\mathrm{p} K$ of 7.4 of the $\alpha$-amino group can be estimated. The difference of 0.7 between the $\mathrm{p} K$ of the $\alpha$-amino group in the free $\alpha$-chain and oxyhaemoglobin, respectively, can be explained by the observation that in oxyhaemoglobin this group is found in the proximity of the terminal arginine of the partner $\alpha$-chain ${ }^{20}$, which is positively charged in the neutral $\mathrm{pH}$ region. 

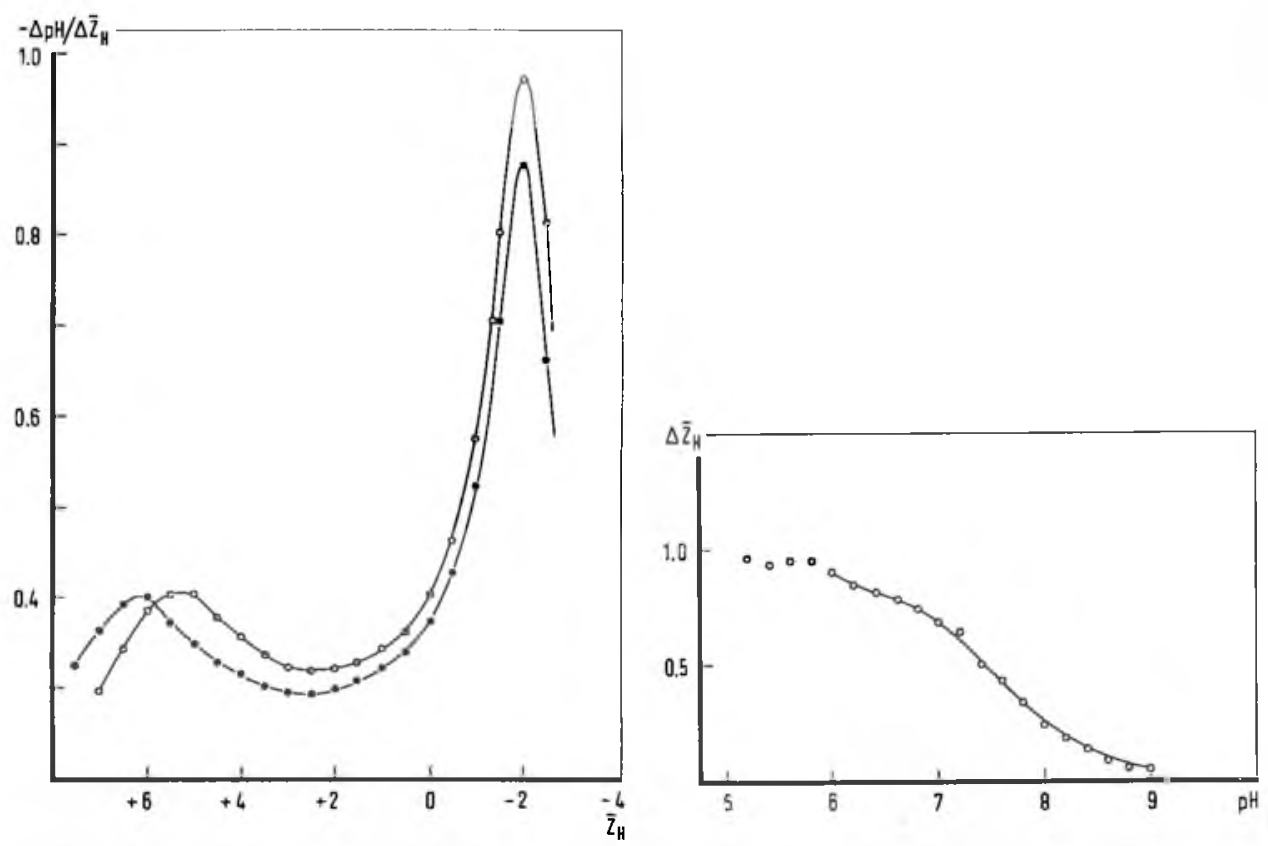

Fig. 9. Differential titration curve of : (O) $\alpha$-chain of human haemoglobin, (O) this chain with $\alpha$-amino group blocked with fluorodinitrobenzene. $I=0.1(\mathrm{KCl}) ; t=25^{\circ} \mathrm{C}$.

Fig. 10. Difference titration curve of $\alpha$-chains of Fig. 9.
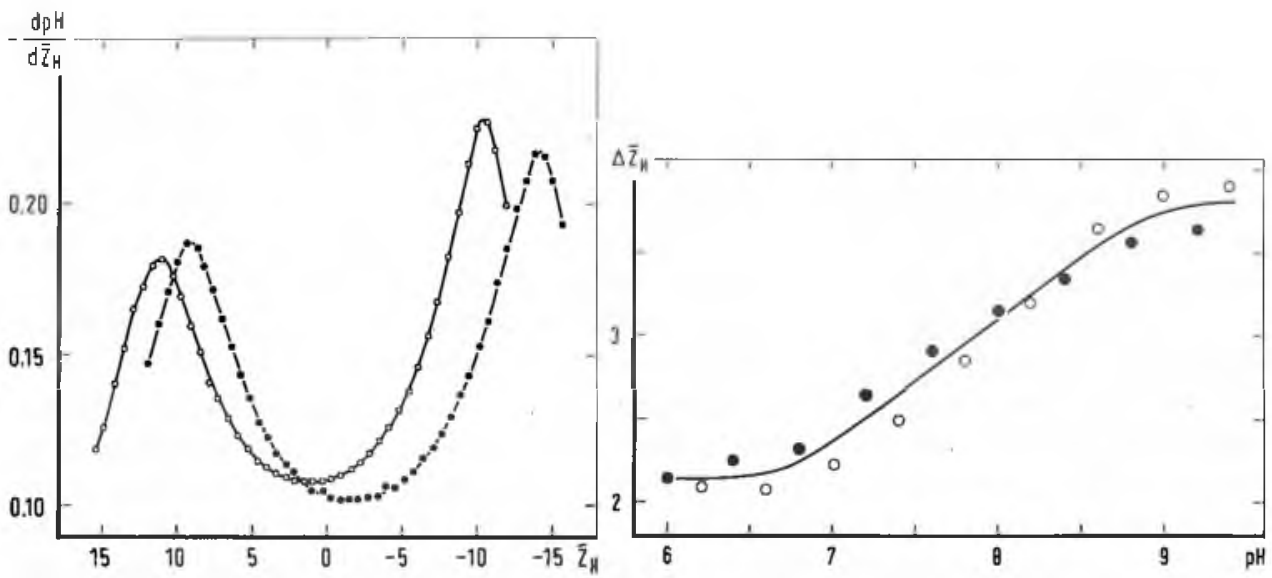

Fig. 11. Differential titration curves of bovine deoxyhaemoglobin: (O) A, (O) B. $I=0.1(\mathrm{KCl}) ; t=25^{\circ} \mathrm{C}$.

Fig. 12. Difference titration curve of bovine haemoglobin A and B; (O) deoxy form, (O) oxy form.

Finally, we give in Figs. 11 and 12 an example of titration curves of two proteins which have small differences in amino acid composition. Figure 11 presents the differential titration curves of bovine deoxyhaemoglobin ${ }^{21} \mathrm{~A}$ and $\mathrm{B}$. These two proteins differ only at three sites in the $\beta$-chains. The residues at places 15,18 and 119 
(counted from the $\mathrm{N}$ terminal end), in haemoglobin A occupied by glycine, lysine and lysine respectively, are in haemoglobin $\mathrm{B}$ replaced by serine, histidine and asparagine (amide form). Indeed, because of the absence of four lysines (two in each $\beta$-chain) in $\mathrm{B}$, the second peak is displaced four units to the right. Furthermore, the peak to peak distance is two units more for haemoglobin $B$ than for haemoglobin A, indicating that the two extra histidines are titratable. The presence of these two histidine residues is also seen in the difference titration curve of Fig. 12, from which moreover an apparent $\mathrm{p} K$ of 7.8 of these groups, both in deoxy- and oxyhaemoglobin, can be read. The X-ray model of haemoglobin gives an explanation for this abnormally high $\mathrm{p} K$ value.

The examples given clearly demonstrate the valuable information that can be obtained from protein titration curves.

\section{REFERENCES}

1 C. Tanford in T. Shedlovsky (Ed.), Electrochemistry in Biology and Medicine, John Wiley and Sons, New York, 1955.

2 J. Steinhardt and E. M. Zaiser, Adv. Protein Chem., 10 (1955) 151.

3 J. C. Kendrew, R. E. Dickerson, B. E. Strandberg, R. G. Hart, D. R. Davies, D. C. Phillips and V. C. Shore, Nature, 185 (1960) 422.

4 M. F. Perutz, M. G. Rossmann, A. F. Cullis, H. Muirhead, G. Will and A. C. T. North, Nature, 185 (1960) 416.

5 L. H. M. Janssen, Thesis, Nijmegen, 1970.

6 C. Tanford, Physical Chemistry of Macromolecules, John Wiley and Sons, New York, 1961.

7 J. J. Hermans and J. Th. G. Overbeek, Recl. Trav. Chim., 67 (1948) 761.

8 C. Tanford, J. Phys. Chem., 59 (1955) 788.

9 C. Tanford and J. G. Kirkwood, J. Amer. Chem. Soc., 79 (1957) 5333, 5340.

10 S. H. De Bruin and G. A. J. Van Os, Recl. Trav. Chim., 88 (1969) 17.

11 C. Tanford and J. G. Buzzell, J. Phys. Chem., 60 (1956) 225.

12 W. J. Leonard, K. K. Vijai and J. F. Foster, J. Biol. Chem., 238 (1963) 1984.

13 B. J. M. Harmsen, Thesis, Nijmegen, 1970.

14 B. J. M. Harmsen, S. H. De Bruin, L. H. M. Janssen, J. F. Rodrigues De Miranda and G. A. J. Van Os, Biochemistry, 10 (1971) 3217.

15 J. Wyman, Jr, Adv. Protein Chem., 4 (1948) 407, 19 (1964) 223.

16 E. Antonini, J. Wyman, M. Brunori, C. Fronticelli, E. Bucci and A. Rossi-Fanelli, J. Biol. Chem., 240 (1965) 1096.

17 M. F. Perutz, H. Muirhead, L. Mazarella, R. A. Crowther, J. Greer and J. V. Kilmartin, Nature, 222 (1969) 1240.

18 J. V. Kilmartin and L. Rossi-Bernardi, Nature, 222 (1969) 1243.

19 R. J. Hill and R. W. Davis, J. Biol. Chem., 242 (1967) 2005.

20 S. H. De Bruin and E. Bucci, J. Biol. Chem., 246 (1971) 5228.

21 L. H. M. Janssen, S. H. De Bruin and G. A. J. Van Os, J. Biol. Chem., 247 (1972) 1743.

J. Electroanal. Chem., 37 (1972) 
